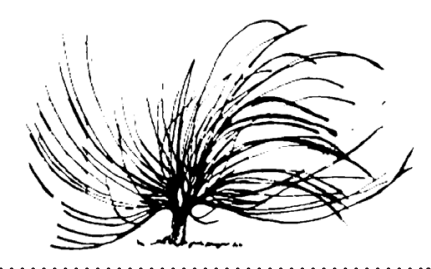

\title{
Determinaciones categoriales y noción conceptual de la educación: tensiones entre el sistema ético indoeuropeo y el asiático-afro-mediterráneo
}

\author{
Ernesto Herra Castro ${ }^{1}$ \\ Universidad Nacional \\ Costa Rica \\ ernesto.herra.castro@una.cr
}

\begin{abstract}
Resumen
El presente trabajo identifica diversos momentos educativos que, en tanto determinaciones categoriales, han quedado subsumidos y dan sentido a la noción concreta, al concepto, de lo que es la educación. De esta forma, la actual preocupación intenta nombrar las tensiones propias que tienen lugar durante el desplazamiento de la centralidad del sistema ético indoeuropeo, surgido desde el siglo XX a. C., al sistema ético asiático-afromediterráneo, nacido en el siglo IV d. C. Dado que estas tensiones forman parte de la presión que como especie humana le añadimos a nuestra madre común aún en la actualidad, se nombran dichos momentos educativos para impulsar otras nociones o posibilidades de educación más que aquellas contenidas en el proyecto de la Modernidad, con el afán de ir más allá que ella.
\end{abstract}

\section{(C) $(\Theta \Theta$}

Recibido: 10 de agosto de 2017. Aprobado: 24 de setiembre de 2018.

http://dx.doi.org/10.15359/rep.13-2.1

1 Docente, investigador y extensionista en la Escuela de Sociología de la Universidad Nacional. Sus problemas y preocupaciones las construye al lado de la Red académica, indígena y rural denominada "Epistemologías del Sur”, impulsada desde esta casa de enseñanza. 
Palabras claves: educación, categorías, conceptos, sabiduría, conocimiento.

\begin{abstract}
This paper identifies various educational moments that, as categorical determinations, have been subsumed and give meaning to the concrete notion, concept, of what education is. In this way the present concern tries to name the tensions that take place during the displacement of the centrality of the Indo-European ethical system, emerged since the XX century BC, by the Asian-Afro-Mediterranean ethical system, emerged since the fourth century AD. Given that these tensions are part of the pressure that we as a human species add to our common mother even today, we name such educational moments to promote other notions and/or educational possibilities more than those contained in the Modernity project to go beyond it.
\end{abstract}

Keywords: education, categories, concepts, wisdom, knowledge.

\title{
Introducción
}

lo largo de nuestro desarrollo evolutivo como especie, la
educación ha fungido como una institución humana de
fundamental importancia para la producción y reproducción de la vida humana articulada a partir de dos momentos que le constituyen como totalidad: la enseñanza y el aprendizaje.

La respuesta científica, como formalización de $u^{2}$ solo tipo particular de sabiduría, ha sido impulsada a partir del siglo VI a. C.; sin embargo, no es sino en la Grecia clásica, siglos IV y III a. C., que el tipo de pregunta presupuesta en el horizonte científico se ha limitado a sofisticar las relaciones de dominio que permiten la centralidad

2 En trabajos anteriores hemos dado cuenta de cómo la ciencia quedó limitada al despliegue de relaciones de dominio que tienen por horizonte de sentido la "riqueza ilimitada", denominada en Aristóteles (2007) “ciencia de adquirir", al tiempo que ha limitado las condiciones de posibilidad para impulsar la producción de la vida comunitaria, denominada en Aristóteles (2007) "ciencia doméstica". Este es el sentido de reflexionar críticamente acerca de la ciencia, en tanto institución humana, en un momento histórico en el que peligra la vida misma en la tierra. 
de privilegios por parte de los sectores aristócratas y oligarcas que administran la política, la filosofía y la guerra (Herra y Navarro, 2014; Herra, 2015; Herra, 2016; Herra y Baraona, 2015; Herra y Baraona, 2017; Herra, 2017a; Herra, 2017b).

Los "núcleos problemáticos" (Dussel, 2015), que han permitido el surgimiento de las distintas respuestas racionales con las que nuestra especie se ha enfrentado al misterio de la vida a lo largo de los circa de 130000 años de su existencia, nos han dotado de herramientas técnicas cada vez más sofisticadas con que hacer nuestra vida posible. La ciencia y el conocimiento son parte de lo producido por nuestra especie para enfrentarse ante lo desconocido. No obstante, esta no es la única respuesta, tampoco la superior. Más aún cuando la racionalidad helena desplegada entre los siglos VI y III a. C., se ha ocupado de reducir a la ciencia y a la filosofía a establecer relaciones de dominio de nuestra especie consigo misma y todas las otras formas de vida (Herra y Navarro, 2015; Herra y Baraona, 2015; Herra y Baraona, 2017).

Lo que intentaré hacer en este breve trabajo es sacar a la luz diversos momentos educativos, que es la forma en cómo he llamado a las determinaciones categoriales que dan forma constitutiva a la dinámica educativa, en tanto concepto que, al ser concreto, “....es la síntesis de múltiples determinaciones, por lo tanto, unidad de lo diverso" (Marx, 2016, p. 21). De esta manera, se trata de mostrar cómo la dinámica educativa que nos atraviesa en la actualidad es, en última instancia, el resultado de las tensiones, confrontaciones, la negación, la resistencia, la transformación con que nuestra humanidad ha logrado habitar el único cuerpo en la vía láctea en capacidad de producir vida tal cual la conocemos.

Para hacer lo anterior, he preparado cuatro trabajos, dos de ellos ya publicados (Herra, 2017a; Herra, 2017b), que intentan situar y caracterizar los diversos momentos educativos impulsados por los cuatro sistemas éticos ${ }^{3}$ por los que ha transitado nuestra mismidad humana y así mostrar cómo estas confrontaciones, negaciones, resistencias y

3 Los cuatro sistemas éticos que ha atravesado nuestra humanidad están conformados por el egipcio-mesopotámico, organizado hacia el IV milenio a. C.; el segundo de ellos es el indoeuropeo, organizado hacia el siglo XX a. C.; el tercero es el afro-asiático-mediterráneo, organizado hacia el siglo IV d. C.; y el último es el sistema ético, que por primera vez es mundial a partir de la imposición militar de la Europa latino-germánica, en lo que en la actualidad es conocido como América desde 1492. Lo anterior le habría permitido a Occidente ser centro de dicho sistema. Sin embargo, las guerras imperiales/coloniales de nuestro tiempo histórico dan cuenta del desplazamiento de dicho centro hacia otras latitudes. 
transformaciones han quedado contenidas en la dinámica educativa que conocemos hasta la actualidad.

Hacer lo dicho nos permitirá evidenciar las tensiones existentes entre la producción y reproducción de la vida, por un lado, y los horizontes de sentido que han impulsado la negación de la vida misma a lo largo de nuestra trayectoria humana en la tierra.

De lo que se trata es de sacar a la luz la representación abstracta a la que se ha visto sometida la dinámica educativa, en tanto síntesis del proceso de pensamiento, y de cómo dicha abstracción tiene concreción en las distintas etapas del pensamiento humano.

Lo que intentaré hacer en esta oportunidad es mostrar cuatro momentos educativos en particular, que se despliegan desde el proceso de imposición del mundo otomano en el territorio ocupado por la Europa latino-germánica a partir del siglo VII de nuestra era. Estos cuatro momentos nos permiten identificar la justificación del desplazamiento espacial del campo por la ciudad y la imposición de la democracia como referente único de lo político; el momento de imposición institucional/ formal de la fe del imperio como único referente de la fe marcado por la práctica litúrgica de la desigualdad; un tercer momento, cuya trascendencia se extiende hasta nuestros días, está caracterizado por la justificación de la muerte del/de la "otro/otra" por su creencia en un Dios falso o inferior, dado que no es el propio, al cual no solo hay que combatir, sino que al pueblo que profese su fe en Él merece la negación de su vida; por último, identificamos un cuarto momento educativo caracterizado por la síntesis teórico/práctica de la filosofía platónica y la aristotélica propia del mundo islámico otomano. Lo anterior ha permitido darle cabida en la actividad filosófica a la idea en tanto tal y a sus significados amplios.

Se trata, junto a Feyerabend (1984), de pensar "la educación -comouna forma de proteger a la gente para que no se deje educar" (p. 150), identificando los tiempos/espacios, así como los fundamentos racionales que han tensado, a lo largo de nuestra existencia humana, la posibilidad de producir y reproducir la vida humana y las otras que hacen a esta posible.

En un tiempo histórico en el que la filosofía y la ciencia moderna han invertido, fetichizado y trastocado el amor a la sabiduría, es clave vaciar y volver a llenar de contenido aquellas instituciones que, en inicio, fueron impulsadas para hacer la vida humana posible, las cuales 
han quedado limitadas a una ética utilitarista, costo-beneficio, en la cual toda forma de vida debe ser controlada y dominada.

\section{Expansión territorial, imposición política y fe: pilares constitutivos del orden grecoromano}

Mi intención de identificar los aportes del sistema interregional asiático-afro-mediterráneo, a saber, el conocimiento y la ciencia, tiene que ver con comprender las manifestaciones de atrofia en la que se encuentra actualmente el sistema educativo formal como un todo. Lo anterior lo señalo, principalmente, porque aún cuando el finlandés, por ejemplo, pueda ser galardonado como el mejor sistema educativo del mundo, este se sitúa en un mundo cada vez más incapaz de sentir empatía por el sufrimiento ajeno. Esto no solo muestra la ausencia de humanidad que atraviesa nuestro tiempo histórico, sino que es evidencia de la crisis de civilización (Baraona y Herra, 2016) que ha puesto en tensión el proyecto contenido en la Modernidad ${ }^{4}$.

A partir de los siglos IV y III a. C., tiempo histórico en el que Grecia retorna a la centralidad de la que una vez fuese desplazada por Macedonia en el mar Mediterráneo, el tipo de pregunta que se impone y que media la clase de relacionamiento de la humanidad consigo misma, y de esta con las otras formas de vida, está mediado por la relación sujeto-objeto. En términos filosóficos este relacionamiento tiene implicaciones tales que aquel/aquella que se logre imponer militarmente sobre el/la "otro/otra" ha culminado por autoproclamarse racionalmente superior. De lo anterior da cuenta el "derecho natural" que tienen los pueblos de guerreros, los cuales, desde la Grecia clásica (siglos IV-III a. C.), logran imponerse militarmente sobre otros (Aristóteles, 2007).

El sujeto en capacidad de hacer la política, la filosofía y la guerra es quien culmina por ocupar el lugar del "ser" de la metafísica griega (Herra y Baraona, 2015; Herra y Baraona, 2017). Lo nombrado, explicado, delimitado, determinado por el sujeto no es nada más que su objeto.

4 He desarrollado una tematización y argumentación de ese tema en dos trabajos que sin temor propondría revisar para aquellos/aquellas a quienes esta discusión les parezca oportuna y pertinente: "Verde que te quiero verde. Incompatibilidades entre nuestra realidad y nuestra subjetividad", publicado en el 2014; y el otro publicado en el 2017, titulado "Hacia una epistemología radical de la descolonización". 
En términos filosóficos, la tradición helena parte de un posicionamiento antropocéntrico que separa nuestra mismidad de las otras formas de vida. Esto lo hace para justificar(se) la superioridad racional humana como muestra de nuestra distinción entre el resto de las formas de vida que debían ser sometidas a las necesidades y pasiones (deseos) humanas. Este posicionamiento epistémico, en concordancia con la metafísica helena, concibe al objeto dominable como physis (lo natural) y nómos (lo humano), noción última que está mediada por convenciones formales (contratos) que hacen posible la convivencia entre helenos (Herra y Baraona, 2015; Herra y Baraona, 2017). De esta forma, la naturaleza, que en otras nociones cosmogónicas es constitutiva de nuestra mismidad y por ende es asumida como madre común, es escindida, según esta tradición, de nuestra mismidad; por lo tanto, no es parte del "ser". Para que ella pueda ser dominada, necesita ser concebida como cosa, como objeto. Quizá sea este el origen de la "crisis ambiental" que actualmente nos atraviesa y es el principal conflicto que reta la supervivencia de la especie humana, lo que ella ha definido como naturaleza, así como toda forma de vida en la tierra tal cual la concebimos.

Alejandro Magno, rey de Macedonia, posterior al asesinato de su padre Filipo II (382-336 a. C.) ocurrido en el 336 a. C., destruyó ese mismo año la ciudad de Tebas, conquistó Atenas y más adelante destruyó el imperio persa de los Aqueménidas, lo que se constituyó en una amenaza constante para los pueblos griegos desde la invasión de Jerjes a Atenas en el 480 a. C., (Pagden, 2014, p. 31).

Hacia el 338 a. C., los alcances del poder macedónico se extendían a lo largo del territorio euroasiático (Aristóteles, 2007). Esto le valió a Alejandro para ser calificado de Magno, no solo por la extensión el territorio conquistado, sino porque gracias a las instrucciones de su mentor, Aristóteles, impuso la monarquía como sistema político, al tiempo que se mostraba "benevolente" con los "bárbaros".

El término "bárbaro" se aplicó a todas aquellas personas que no hablaban griego, no eran atenienses y, por lo tanto, cuando hablaban se escuchaba a los oídos de los griegos como si estuvieran diciendo "bar bar", de donde se desprende este término, que en la práctica formal permitió organizar un complejo sistema social, cuyo fundamento material se basó en la esclavitud, organizada en torno a privilegios de aristócratas y oligarcas (Herra y Baraona, 2015). 
Posterior al siglo II a. C., momento en el que griegos y romanos conforman un solo pueblo, el tipo de racionalidad que permitió la organización de Roma fue el mismo que dio la posibilidad a Grecia de dotarse de un complejo, estructurado y desigual sistema estatal, el cual quedó subsumido en el orden de privilegios republicanos, primero, y posteriormente imperiales.

No es que en los otros pueblos no se hubiesen diseñado mecanismos, estructuras o sistemas de trabajo cuyo horizonte de sentido se dirigió a la "apropiación excluyente del excedente de la comunidad" (Dussel, 2014). Lo que sí constituye un hecho novedoso es la racionalización de un orden fundamentado en la desigualdad hacia el/la "otro/ otra", que es incorporado como cosa viva, como mecanismo creador de valor en las relaciones sociales helenas, que brinda las condiciones de posibilidad al pueblo heleno para edificarse como el único sujeto en condición de hacer la política, la filosofía y la guerra. Esto es solo posible en la medida que el/la "otro/otra" excluido/a sea constituido/a como su objeto.

El pensamiento heleno no le ha brindado únicamente la justificación racional al pueblo romano para dominar a otros, sino que este le ha impuesto un lugar desde donde pensar: "fuera de Atenas no hay nada más que ciudades compuestas, ciudades con mezclas de todos los orígenes. Sólo los atenienses son autóctonos puros sin mezcla, sin aleación de no-autóctonos" (Detienne, 2005, p. 18). Los "otros" (los niños, los esclavos, los bárbaros, las mujeres no oligarcas o aristócratas, los extranjeros) quedan excluidos de la posibilidad de "ser" reconocidos como parte de "demos" (pueblo) en capacidad de hacer la política, la filosofía o la guerra. De esta forma, oligarcas y aristócratas garantizan, a través del control y de la administración hegemónica del aparataje institucional del Estado, la reproducción de un orden sexista/racista/clasista. Lo anterior lo logran a través de un sistema político que permite garantizar la continuidad de las condiciones desiguales imperantes y da las condiciones de centralidad a oligarcas y aristócratas; se denomina desde entonces "democracia". Así, el orden político queda reducido a lo "democrático".

Ante los elementos anteriores, quisiera proponer un primer momento educativo anterior al sistema interregional asiático-afro-mediterráneo, pero que, de alguna manera, define los linderos espaciales de los proyectos políticos posteriores, caracterizado por la centralidad 
que tendrá, a partir de este momento, el espacio social de la ciudad frente a lo que se definirá, posteriormente, como la ruralidad. Todo lo que no sea ciudad (sujeto) será ruralidad (objeto). Quisiera, entonces, proponer este primer momento como momento de imposición espacial y político para la desigualdad.

La monarquía macedónica expandida por Alejandro es considerada el primer imperio europeo, del que posteriormente Roma fuera sucesora. Lo anterior se dio como resultado de "la unión del saber y el conocimiento con el poder, de la fusión de la ciencia y la exploración con el dominio y el asentamiento", logradas gracias a la capacidad expansiva de su maquinaria de guerra, la cual reprodujo el orden republicano romano, ante "la capacidad de transformar un gran cuerpo de hombres en un instrumento unido para la destrucción" (Pagden, 2014, p. 38).

El ejército a disposición de Alejandro ha sido el más grande con el que haya contado Grecia a través de su historia. Estuvo conformado por 43000 soldados de infantería armados y entrenados en el "arte de la guerra", así como por 5500 jinetes (Pagden, 2014, 32-33).

La ausencia de un dispositivo tecnológico que les permitiera, a los demás pueblos, enfrentarse a las maquinarias de guerra y destrucción en las que se convirtieron el Imperio de Alejandro (336-323 a. C.) y el Imperio romano (27 a. C.-476 d. C.) garantizó la expansión de ambos por la vía de la dominación y la esclavitud. De esta forma, una vasta gama de naciones, nacionalidades, pueblos y comunidades con cosmovisiones, creencias, tradiciones, ritos, rituales, métodos de organización, mecanismos de relación y economías muy diversas y distintas, a la dinámica productiva helena, quedó atrapada en los circuitos de reproducción de valor grecoromanos. Si bien, las relaciones vasallo-feudales ${ }^{5}$ datan de la constitución de la República de Roma (509 a. C.), estas se encuentran contenidas en el proyecto universal con el cual la expansión de la monarquía macedónica de Alejandro y, posteriormente, el Imperio romano se logran imponer y normalizar como parte del conjunto de las dinámicas de nuestra especie consigo misma. Esto

5 "Las relaciones vasallo-feudales fueron un conjunto de prácticas fundamentadas en la sumisión, la lealtad y el respeto que le debía el vasallo a su amo, denominadas Fidélitas, y este último le debía protección y cuidado a quien era de su propiedad: Fides. Este tipo de relaciones de inferioridad/superioridad sobre la línea de lo humano -como las llama Grosfoguel- datan de la constitución de la República de Roma en el 509 a.C., las cuales atraviesan su época de Imperio (27 a.C.-476 d.C.) y se extienden hasta su caída bajo el mando del Imperio otomano en el 711 de nuestra era" (Herra y Navarro, 2014, p. 26). 
solo ha sido posible a través de "una mezcla de fuerza bruta y cierta base ideológica" (Pagden, 2014, p. 19).

Al igual que el orden democrático del Estado heleno giró en torno a oligarcas y aristócratas, la República de Roma garantizó privilegios a los patricios, los cónsules y los procónsules. A diferencia del orden democrático del Estado heleno, la República de Roma sí aceptó la participación de mujeres etruscas en la división de poderes que fue el sistema político ideado para mantener el poder en manos de una minoría. Tal participación femenina en la división de los poderes de la República de Roma tuvo que ver con la posición económica que estas jugaban en su dinámica social. De esta forma, la administración y el control del poder por parte de una minoría para hacerse del excedente de la fuerza del trabajo socialmente producido se complejiza en tanto ya no serán, en adelante, jerarquías de poder únicas, como el sexismo institucional del proyecto democrático heleno, las que se impongan para inferiorizar (racializar) al/a la otro/otra. El nuevo orden romano deja en evidencia que el sexo, la clase o la etnia operan en una estructura imbricada, organizada en torno a los privilegios de oligarcas y aristócratas que son solo posibles mediante la reproducción de relaciones de tipo vasallo-feudal que giran alrededor de estos. No será casualidad que, en 1846, esto llevará a Marx a pensar la esclavitud como "una categoría económica de la más alta importancia" (1966, p. 538) y a Franz Fanon, sociólogo colonizado de Martinica, quien se sabe colonizado, a identificar que "lo que divide al mundo es primero el hecho de pertenecer o no a tal especie, a tal raza" (2012, p. 34).

El Imperio romano (27 a. C.-476 d. C.), cuyo término latín significa "el dominio de los romanos", culminó por convertirse en una estructura organizada para la "explotación despiadada de pueblos en gran medida indefensos, menos complejos tecnológicamente, por la fuerza de los avances tecnológicos..." (Pagden, 2014, p.18) de los/las "otros/otras. Por esta razón, Roma se logrará expandir hasta su momento más glorioso, comprendido entre los años 98 y $117 \mathrm{~d}$. C., con el emperador Trajano (53-117 d. C.) a la cabeza del Imperio, y alcanzará dimensiones tales que le ubicarán entre el mar Rojo y el golfo Pérsico al este; el océano Atlántico hasta el mar Caspio por el oeste; el Sahara al sur; así como Caledonia, los ríos Rin y Danubio al norte. Roma llegará alcanzar una superficie máxima estimada en unos 6,5 millones de $\mathrm{km}^{2}$. 
Las confrontaciones constantes por el poder en este vasto territorio permitieron que Dioclesiano, reconocido héroe militar, llegara a ser proclamado emperador romano posterior a la muerte de Caro y su hijo Numeriano, acaecida en batalla contra los persas, hacia el 284 d. C.

Dioclesiano creó un orden romano muy diferente a los anteriores. Este se hizo acompañar de un coemperador de Occidente, llamado Maximiliano, en el 285, así como de una suerte de príncipes herederos, para lo cual nombró a Constancio y Galerio, dos de sus más leales súbditos. Estos fueron erguidos como césares y dieron origen a un nuevo régimen, denominado tetrarquía, lo que divide el territorio en Imperio de Occidente, cuya sede debía permanecer en Roma, e Imperio de Oriente, cuya sede se ubicó en Turquía y su proyección debía continuar hacia el Oriente (Pagden, 2014).

En una fecha incierta que se sitúa entre el 300 y el 324, la Iglesia cristiana de Hispania celebró su primer concilio, conocido como el "Concilio de Elvira", al que asistieron diecinueve obispos y veintisiete presbíteros de la Península Ibérica, a instancias del consejero, obispo y padre de la Iglesia de hispánica: Osio de Córdoba. Lo anterior fue parte de la lectura que como estadista realizó el emperador Constantino I, quien calculó, de forma meticulosa, la expansión del Imperio de Roma aún después de su muerte (Johnson, 2010).

En ese Concilio se fijaron ochenta y un cánones disciplinarios entre los que, en términos de importancia geopolítica, se encuentra el interés de la Iglesia cristiana, que es la Iglesia de Hispania, en el que se definían distancias con las religiones paganas, o sea todas aquellas que no fueran la cristiana, así como la separación con las comunidades judías. Al tiempo que ocurría lo anterior, Osio de Córdoba instaba al emperador Constantino I para apoyar a la comunidad cristiana a través del Edicto de Milán, promulgado en dicha ciudad en el año 313, el cual reconoce la libertad de religión, por lo que brinda protección a la Iglesia cristiana y a otras denominaciones religiosas. Dicho edicto fue firmado por el emperador Constantino, de Occidente, y el emperador Licinio, de Oriente (Pagden, 2014).

La rivalidad por el control absoluto del Imperio de Roma estuvo en constante puja, la cual desencadenó numerosas guerras entre ambas falanges, hasta que en el año 324 Constantino I derrota definitivamente a Licinio, lo hacen preso y, posteriormente, ordenan su asesinato, alegando conspiración en contra del emperador Constantino. 
Ante el apoyo mostrado por parte del pueblo cristiano al emperador Constantino I en las confrontaciones con Licinio, durante el año 325 , como continuación de lo ya iniciado anteriormente con Osio de Córdoba, el Imperio romano convoca al "Concilio de Nicea I" y se declara la libertad de los cristianos para reunirse y practicar su fe. Aún cuando es en el año 337, en vísperas de su muerte, que se da la conversión de Constantino al cristianismo, es hasta el año 380, en el Senado romano, a través del "Cunaos Populos", que se promulga la obligatoriedad de todos los pueblos a adherirse a la Iglesia cristiana, ya que la suya ha sido asumida como la única religión del Imperio (Johnson, 2010; Pagden, 2014).

Dado lo anterior, el sociólogo y epistemólogo aimara-boliviano Juan José Bautista (2010) señala:

desde que la iglesia cristiana se convierte en imperio bajo Constantino en el siglo IV, ella se convierte en religión de dominación. Si antes Roma era pagana, ahora se convertirá en divina, el Cesar cederá su lugar al Papa y los generales a los obispos. Los filósofos estoicos desaparecerán poco a poco para dar lugar a los padres teólogos. San Agustín en su disputa con Pelagio, demostrará la superioridad del nuevo sistema de creencias y así Roma la eterna, sobrevivirá todavía algunos siglos (Bautista, 2010, p. 236).

Ante lo previo, quisiera proponer la existencia de un segundo momento educativo, caracterizado por la imposición de una sola religión, de una sola fe para la unificación de un vasto, complejo y diverso territorio, el Impero romano, por lo que deseáramos sugerirlo como momento de imposición institucional/formal de la fe del Imperio cuya expresión práctica tiene que ver con la religiosidad de la desigualdad.

\section{Disputas disciplinares más allá de Dios}

Los elementos anteriores crisparon la tensión ya existente entre teólogos y filósofos. Los filósofos planteaban que Dios es el creador desde la eternidad y que el mundo ha sido creado desde esta eternidad. Los teólogos señalaban lo anterior como un error, puesto que para ellos debe existir un comienzo del tiempo en el cual la creación de Dios es un momento dentro del tiempo. Esto era criticado por la comunidad 
de filósofos por transferir la dimensión temporal a Dios y eliminar, de esta forma, la distinción entre uno y el otro; por lo tanto, homologarlos. Esta discusión, aún en la actualidad, no es asunto insignificante, menos cuando la religión continúa representando una de las principales estructuras de poder mediante las cuales los proyectos imperiales continúan en expansión.

El estoicismo, corriente filosófica que entró en Roma hacia el 150 a. C., es, quizá, la escuela neoplatónica y postaristotélica que experimentó el mayor auge y crecimiento en el pensamiento romano, durante su conformación imperial. Su incorporación en el marco institucional romano no dejó de experimentar tensiones y resistencias, al confrontarse con el absolutismo estatal y la esclavitud, superando así los sesgos clasistas, si se quisiera pensar así, de las posturas aristotélicas y platónicas de las que esta escuela se nutría. En términos prácticos, mientras que en el marco individual los ciudadanos romanos encontraban en el estoicismo la posibilidad de humanizarse, en la realidad seguían siendo la nobleza y aristocracia las que ocupaban los aparatos de poder y control compartidos, ahora, con la naciente oligarquía vinculada al comercio y la aristocracia asociada a la Iglesia cristiana, la cual logró desarrollarse, teológicamente, y expandirse en tiempos de la "pax romana" (Pagden, 2014).

De esta forma, inicia un largo período de la historia occidental, ya que no es un hecho que le aconteció a la humanidad toda, denominado Edad Media (siglos IV-XIV). Este es un período de expansión de la Iglesia cristiana en cada estructura del orden social organizado por Roma cuando su territorio había sido ocupado, era administrado y controlado por el mundo islámico otomano. A partir de ahora será el criterio teológico de la Iglesia cristiana, en el mejor de los casos, el que se impondrá como hegemónico, hasta que Europa cuente con condiciones racionales para renacer de su oscurantismo religioso: Renacimiento (siglos XI-XIII).

La expansión desarrollada por la Iglesia cristiana le permite una centralidad sin precedentes en el orden teológico romano, a través de la reproducción de relaciones vasallo-feudales en las distintas jerarquías de poder que se estructuran en torno a la centralidad social, política y económica que esta ocupara. Este tipo de relacionamiento se reprodujo en Roma desde el año 509 a. C.; atravesó su época imperial (27 a. C.476 d. C.) hasta la capitulación del Imperio, obra del Hérulo Odacro, 
quien derrocó al emperador Rómulo Augusto, al enviar las insignias imperiales a Zenon, emperador de Oriente, el cual continuaría, ahora como Imperio Bizantino, hasta 1453 (Pagden, 2014). Si bien, la dinámica romana se reprodujo a lo interno de la Europa latino-germánica, es importante dejar en claro que este territorio había sido ocupado por el mundo islámico otomano desde el 711 de nuestra era.

El Imperio romano estaba conformado por un vasto territorio organizado para la constante expansión de Roma, aun cuando hacia lo interno el Imperio se encontraba corroído. La gran diversidad de credos, tradiciones, gastronomías, historias, etc. había sido aplacada por la imposición de un solo credo, una sola tradición, una sola historia que, a partir de ahora, se impondría como la única y verdadera: la historia de Roma.

A partir del primer decenio del siglo VII de nuestra era, el Imperio romano y Persia (actualmente Irán) se vieron enconadas en una serie de confrontaciones bélicas en las que cada uno le quitaba, reiteradamente, el territorio recién adjudicado al otro. Aunado a lo anterior, en el 636, los árabes habían invadido y tomado tanto Judea como Siria; en 640 invadieron Egipto; y en 634, 637, 642 y, finalmente, 651 los árabes se enfrentaron con los persas hasta triunfar (Pagden, 2014; Burckhardt, 2008; Asimov, 2011).

La campaña militar árabe prosiguió y, desde la segunda mitad del siglo VII, había logrado expandirse por territorios del Imperio romano de Occidente, constituido formalmente desde el $395 \mathrm{~d}$. C., por el emperador Teodosio I. De esta forma, los otomanos logran conquistar el territorio de lo que fuese uno de los más grandes proyectos expansionistas de todos los tiempos que, al haber sido derrotado por ellos, pasaría a denominarse "Imperio Bizantino", nombre griego por el que se conocería Constantinopla hasta su capitulación en 1453 (Pagden, 2014; Burckhardt, 2008; Asimov, 2011).

Una de las principales razones por las cuales el sector árabe logró triunfar frente al proyecto imperial romano tiene que ver con que parte importante de la población oprimida, desposeída, empobrecida que había sido negada por parte del orden romano se había volcado en su contra. Los credos, la religión, la fe, así como la vida misma de aquellos/ as considerados/as como "los/as otros/as", "los/as nadies" cobraron un nuevo vigor con la llegada y expansión de las comunidades musulmanas sobre tierras cristianas y esto tiene explicación. Para el pensamiento islámico, el cual está basado en las enseñanzas de Mahoma reunidas en 
el Corán, el judaísmo y el cristianismo constituyen un mismo tronco unificado, cuya doctrina tiene como antecedente a Abraham, el primero de sus profetas. De esta forma, judaísmo, cristianismo e islám parten de la fe en un Dios único incondicionado, que, por una parte, es incomprensible en su esencia y excelso sobre todas las cosas y, por otra, se manifiesta continuamente tanto en el mundo creado por Él como por medio de sus mensajes sagrados. Este último, desde los comienzos de la humanidad, ha ido comunicando a los pueblos por boca de sus enviados o profetas (Burckhardt, 2008, p. 32), partiendo de Abraham, como el primero de los profetas según se mencionó y acorde con la tradición monoteísta, continuando con Moisés, Cristo y Mahoma.

La guerra, según la tradición islámica, está justificada en aquellos casos en que la fe en el Corán o los pueblos, cuyas relaciones espirituales están establecidas en él, están siendo hostigados por otras tradiciones de fe, aun en contra de la herencia abrahámica, lo que da a los musulmanes "el derecho a empuñar las armas contra ellas". De esta forma,

el que perece en la "guerra santa" muere "testigo" del mensaje divino del Islam y gana el Paraíso. Si un enemigo se rinde antes de caer en manos de los musulmanes, hay que concederle la inmunidad, el amān; si es pagano, tiene que aceptar el Islam para salvar la vida; si pertenece a la "gente del libro (sagrado)", es decir, si es judío o cristiano, puede optar por seguir practicando su propia religión bajo la condición de reconocer la protección del Islám (Burckhardt, 2008, p. 32).

Ante lo anterior, quisiera proponer aquí un tercer momento educativo, el cual, según sus características, he llamado justificación teológica de la muerte del/de la otro/otra.

Es solo a partir de la justificación teológica de la muerte del/de la otro/otra que después de tantos siglos de expansión del Imperio romano los árabes, de tradición musulmana, lograran conquistar España en menos de tres años y dominarla e integrarla a su territorio hacia el 713 de nuestra era (Burckhardt, 2008).

Uno de los principales aportes de la filosofía árabe fue la "reconciliación" o "síntesis" que estableció el pensamiento islámico entre la filosofía aristotélica, caracterizada por un pensar rigurosamente metódico que procede de demostración en demostración, con la filosofía 
platónica que impulsa la búsqueda constante de la esencia de los hechos y fenómenos que constituyen "la realidad". Según Burckhardt (2008),

el pensamiento aristotélico se ocupa principalmente de las relaciones lógicas sobre determinado nivel de existencia mientras el pensamiento platónico percibe el carácter simbólico de una cosa, mediante el cual está puesta en una relación vertical con las realidades de órdenes superiores (p. 164).

Ambos enfoques pueden ser conciliados en la medida que se logre identificar las diferencias y establecer tanto los límites como los diálogos entre ambos. De esto eran conscientes los filósofos árabes y de esto aprendió, posteriormente, la Europa medieval.

Uno de los principales ejes para establecer dicha reconciliación epistémica tiene que ver con la identificación común del lugar desde donde surgen las preocupaciones:

Ese eje fue el dogma de la unidad de Dios, y este dogma tiene, por decirlo así, dos caras distintas: por un lado, afirma que sólo Dios está por encima de todos los mundos y, por otra parte, de él resulta que todo lo existente participa necesariamente en el ser de Dios. Existe un solo ser. Por tanto, la pluralidad nace de la unidad y, sin embargo, no sale nunca de ella (Burckhardt, 2008, p. 158).

La anterior es otra noción completamente de la tradición greco/romana-cristiana, en la que lo uno y lo otro se oponen, se confrontan, se niegan.

Según la tradición islámica, el ser humano tiene la capacidad de identificar que su "ser" está compuesto por otras substancias distintas de la materia que compone su cuerpo, como lo serían "la percepción, el pensamiento y el movimiento propio". Sin embargo, el espíritu, que consiste "en el acto puro de conocer", tiene algo mucho más profundo en su mismidad que constituye el alma, la cual "gracias a la conciencia y a sus facultades racionales contiene al cuerpo" (Burckhardt, 2008, pp. 159-160).

La filosofía árabe realiza una propuesta de círculos concéntricos, a través de la cual es posible identificar la estructura esencial de los seres humanos y la de todo el universo, ya que, según esta postura, 
los distintos grados de realidad existen antes que los seres individuales que participan en ellos. Si el mundo corpóreo no estuviera contenido, de principio y conforme a su ser, en el mundo psíquico, no existiría la percepción; las impresiones que recibimos del mundo exterior, no serían más que casualidad incoherente. Y si tanto el mundo corpóreo como el psíquico no estuvieran contenidos en el espíritu, no existiría un conocimiento generalmente válido más allá del individuo. Por consiguiente, podemos hablar no sólo de un universo material, sino también de otro psíquico y de otro espiritual y de que uno contiene al otro... (Burckhardt, 2008, p. 160).

Han sido necesarias las extensas citas anteriormente utilizadas, ya que ellas permiten decir que, a diferencia de la tradición cristiana impulsada por San Agustín (la cual señala al cuerpo como cárcel del alma), en la tradición islámica (que predominó desde el siglo VII hasta el XIV en el territorio europeo), el alma contiene al cuerpo y, por vez primera, esto le permite al ser humano situarse en el centro de las relaciones sociales, desplazando así de su centralidad al orden religioso impuesto por la cristiandad.

Durante este proceso, Europa aprendió de la lengua, la cultura, las formas de relacionamiento, las instituciones, la filosofía griega que había perdido desde mucho tiempo antes de que el cristianismo se convirtiera en religión oficial del Imperio y del poder de Roma: cristiandad. Lo anterior refuerza el señalamiento de la pedagogía crítica que ubica a los árabes como los "maestros y educadores del Occidente latino". Koyré (1985) señala:

He subrayado maestros y educadores, y no sólo y simplemente, tal como se ha dicho a menudo, intermediarios entre el mundo griego y el latino. Pues si las primeras traducciones en latín de obras filosóficas y científicas griegas fueron hechas no directamente del griego, sino a través del árabe, no fue solamente porque no había ya, o no había aún, nadie en Occidente que supiera griego, sino también, y quizá sobre todo, porque no había nadie capaz de comprender libros tan difíciles como La Física o La Metafísica, de Aristóteles, o el Almagesto de Tolomeo, y porque sin la ayuda de Fārābî, Avicena o Averroes, los latinos lo habrían 
conseguido nunca. $Y$ es que no basta saber griego para comprender a Aristóteles o Platón -error frecuente entre los filósofos clásicos-; hay que saber, además, filosofía. Ahora bien, de esto los latinos no habían sabido nunca gran cosa (Koyré, 1985, pp. 1718. Citado en Bautista, 2010, p. 243).

Lo anterior tuvo implicaciones en el hecho de que por sus conocimientos en álgebra "óptica, astronomía, química, farmacia, medicina el mundo musulmán estuvo unos 400 años adelantado de la periferia europea" (Dussel, 2009, p. 40).

De este modo, quisieramos culminar este breve trabajo proponiendo un cuarto momento educativo denominado síntesis platónica/ aristotélica, dados los elementos recién caracterizados. Este surge en un contexto de predominio islámico en el que se establece una propuesta que intenta hilvanar la tradición del pensamiento aristotélico con aquella proveniente del pensamiento platónico, las cuales han quedado subsumidas en el formalismo científico. Es importante detenerse y señalar que este momento emerge como consecuencia de las dinámicas geopolíticas del contexto interregional eurasiático de este periodo y no como un impulso "natural" contenido en la ciencia.

\section{Balance provisional de los cuatro momentos educativos propuestos}

Cuando se intenta pensar la educación como práctica comunitaria, hemos debido identificarla como aquella acción coherente que le ha permitido a nuestra humanidad aprehender de la realidad, para así aprender y transmitir, a los/as suyos/as, los saberes pertinentes para hacer la vida posible. Sin embargo, el proyecto de dominio propio de la racionalidad helena, retomada posteriormente por Occidente para imponerse como centro del sistema mundo moderno/colonial (1492-actualidad), colapsa la formalización institucional de lo educativo con lo que es, en sí, la educación.

Para lograr lo anterior, propusimos en este documento un primer momento educativo impulsado en el sistema interregional asiático-afro-mediterráneo, la humanidad toda, le he denominado momento de imposición espacial y política para la desigualdad, al imponerse, en este contexto, un tipo de racionalidad válida y posible solo en torno a la ciudad. Según esta, todo lo que no es ciudad será concebido como 
ruralidad, al tiempo que el tipo de relaciones, formas de vida, horizontes de sentido que se producen en la primera se imponen sobre aquellas desarrolladas en la segunda. Es este el momento en que la ruralidad queda atada al ritmo, a las formas de vida, al tipo de relacionamiento que se produce en la ciudad sobre aquellos que se producen en la ruralidad. Se crean las condiciones jerárquicas y discursivas de superioridad urbana sobre la inferioridad rural.

Lo otro tiene que ver con el tipo de política y relaciones políticas por los que la "democracia" ha culminado por imponerse como sistema político hegemónico a escala planetaria. Este sistema de organización y representación política ha sido posible solo a partir de la inferiorización y esclavitud del/de la "otro/otra", que comenzó por ser un/a "bárbaro/a", extranjero/a, niño/a o mujer en Atenas, para culminar constituyendo el complejo orden jerárquico que, de manera imbricada, nos atraviesa en la actualidad. Sin embargo, bajo ninguna circunstancia, la "democracia", por mejor de los sistemas de organización y representatividad política que sea, puede percibirse a sí mismo o autoproclamarse como "el mejor de los sistemas", en el tanto no haya saldado y, por el contrario, acentúe las relaciones de desigualdad previamente existentes y propicie otras nuevas, más sutiles y silenciosas.

Al segundo momento educativo, caracterizado por la imposición de una sola religión sobre todas las otras formas de expresión religiosa o tradiciones de fe, le he denominado momento de imposición institucional/formal de la fe del imperio, cuya expresión práctica tiene que ver con la religiosidad de la desigualdad, por ser este el momento en el que se universaliza y totaliza la noción de un Dios único para un conjunto de pueblos ubicados en un vasto, complejo y diverso territorio compuesto por naciones, nacionalidades, pueblos y comunidades igualmente diversos. A partir de ahora, será la práctica y relación cotidiana que una fe y un credo mantengan con el poder lo que marcará una distancia profunda entre el cielo y el infierno. Aún cuando en un primer momento son los/as pobres, los/as miserables, los/as excluidos el sujeto histórico por el que apuesta el Evangelio, será la imposición de una única tradición de fe, de una única religión a partir de un solo tipo de traducción del texto bíblico, vinculada y aliada al poder de Roma, la condición de opresión que le permitirá a la Iglesia de Roma gozar de centralidad y monopolio en el ejercicio del poder. 
En esta investigación, se logró identificar un tercer momento educativo vinculado con las pasiones ligadas a la fe, que han justificado, a lo largo de nuestra historia, la negación de la vida del/de la "otro/otra" cada vez que este/esta no comparta mi fe, mis creencias, mis valores. Este momento no solo ha crecido en magnitud, sino que la sofisticación tecnológica de nuestro días demuestra que lejos de ser amor, vida, misericordia, aspectos en los que concuerdan las tres grandes tradiciones monoteístas, la praxis de su fe demuestra lo turbio, enrarecido, trastocado e invertido de la comprensión de su dios por parte de los pueblos que profesan fe no solo en él, sino en el mercado, el capital y el dinero.

Hemos propuesto un cuarto momento educativo, desarrollado en un contexto de predominio islámico, en el que se establece una propuesta de síntesis entre el pensamiento aristotélico y el platónico, que no había sido posible de lograr por la propia filosofía helena. Esta síntesis tiene que ver con aplicar una visión que trasciende la dualidad racional de la tradición judeocristiana, la cual culmina por imponerse en el proyecto civilizatorio grecoromano posterior al siglo IV d. C. A este momento, que he denominado momento de síntesis platónica/aristotélica, lo insto como posibilidad para arriesgarnos a pensar más allá de la tradición que se nos ha impuesto, tanto en lo científico y lo educativo como en lo filosófico. Se trata de trascender el horizonte de sentido de la racionalidad y la ética del dominio, con el propósito apostar a una racionalidad ética para la vida comunitaria.

Los cuatro momentos educativos identificados a lo largo del presente documento (momento de imposición espacial y política para la desigualdad; momento de imposición institucional/formal de la fe del imperio; justificación teológica de la muerte del/de la otro/otra; y momento de síntesis platónica/aristotélica) se constituyen en determinaciones categoriales que forman parte de la noción concreta que existe en torno a lo que es la educación. Identificar lo anterior nos permite tener claridad de los proyectos, posibilidades o limitaciones contenidas en la producción de nuestra vida humana, a partir del desarrollo de las condiciones técnicas para ello. Sin embargo, como se ha podido observar a lo largo de este trabajo, la negación de la vida ha ocupado un lugar de predominio en el horizonte de sentido con el que algunos pueblos han impulsado sus mitos y utopías.

La dinámica constante en los desplazamientos territoriales, que ha acompañado la historia de las tres grandes tradiciones monoteístas 
(islam, judaísmo, cristianismo), es parte constitutiva de la tensión política, social, religiosa, científica o filosófica con la que unos y otros han logrado poner en riesgo a todas las formas de vida existentes en la Tierra. De esta forma, muestran que, lejos de actuar a favor de la creación de Dios, actúan en su contra.

Si bien los mitos y utopías nos han permitido cobrar conciencia de que existe la infinitud humana, a través de nuestra propia creación, son ellos responsables de nuestra propia finitud. De esta manera, lejos de producir vida, las dinámicas educativas existentes aún en la actualidad están atravesadas por mecanismos especializados en su negación. Tener claridad de ello podría ser la distinción entre una educación para la vida y una motivada por su dominio, su control o su dominación.

\section{Referencias}

Aristóteles. (2007). La política. Ciudad de México: Editorial Época. Asimov, I. (2011). El cercano oriente. Madrid: Alianza Editorial. Baraona, M. y Herra, E. (2016). Danzando en la bruma junto al abismo. Las cuatro crisis y el futuro de la humanidad. San José: Editorial Arlekín.

Bautista, J. (2010). Crítica de la razón boliviana. Elementos para una crítica de la subjetividad del boliviano con conciencia colonial, moderna y latino-americana. Bolivia: Rincón ediciones.

Burckhard, T. (2008). La civilización hispano-árabe. Madrid: Alianza Editorial.

Detienne, M. (2005). Cómo ser autóctono. Del puro ateniense al francés de raigambre. Buenos Aires: Fondo de Cultura Económica.

Dussel, E. (2009). Ética de la liberación en la edad de la globalización $y$ de la exclusión. Madrid: Editorial Trotta, S. A.

Dussel, E. (2014). 16 tesis de economía política. Interpretación filosófica. Ciudad de México: Siglo XXI Editores.

Fanon, F. (2012). Los condenados de la tierra. Ciudad de México: Fondo de Cultura Económica.

Feyerabend, P. (1984). Diálogo sobre el método. En varios: Estructura y desarrollo de la ciencia. Madrid: Alianza Editorial.

Herra, E. y Navarro, L. (2014). Verde que te quiero verde. Incompatibilidades entre nuestra realidad y nuestra subjetividad. Práxis. Revista de filosofía, 72, 25-40. 
Herra, E. (2015). Sociedad/Comunidad: Relaciones de Adaptación/ Resistencia al Proyecto Contenido en la Modernidad: Lecciones Aprendidas a Partir de la Experiencia en Educación Popular/Comunitaria/Rural en Corral de Piedra, Nicoya (2011-2013). Ensayos pedagógicos, $X(1), 125-140$.

Herra, E. (2016). Educación formal/educación popular: Dinámicas de adaptación y resistencia a la modernidad. Experiencia recorrida en la provincia de Guanacaste, Costa Rica (2012-2013). ABRA. Revista de la Facultad de Ciencias Sociales, 36(52), 1-15.

Herra, E. y Baraona, M. (2015). El Estado como fundamento del proyecto Imperialista. En M. Oliva (Presidencia), Coloquio Internacional Antiimperialismo Latinoamericano: historia, memoria, tradiciones, legados y prácticas contemporáneas. Ponencia llevada a cabo en el XII Congreso de la Sociedad Latinoamericana de Estudios Latinoamericanos y del Caribe (SOLAR), Heredia, Costa Rica.

Herra, E. y Baraona, M. (2017). Hacia una epistemología radical de la descolonización. Práxis-revista de filosofía, 75, 9-24.

Herra, E. (2017a). Determinaciones abstractas y noción conceptual de la educación. Una lectura crítica a la acumulación del saber. ABRA. Revista de la Facultad de Ciencias Sociales, 37(55), 1-17.

Herra, E. (2017b). Determinaciones categoriales y noción conceptual de la educación. Una lectura crítica en torno al Sistema interregional Indoeuropeo. Ensayos pedagógicos, 12(2), 1-21.

Jhonson, P. (2010). La historia del cristianismo. Barcelona: Zeta bolsillo.

Marx, C. (2016). Elementos fundamentales para la crítica de la economía politica (Grundisse) 1857-1858. Tomo I. Ciudad de México: Siglo XXI Editores.

Pagden, A. (2014). Pueblos e imperios. Barcelona: Debate. 
